\title{
MATERNIDADE NA ADOLESCÊNCIA: escolha ou fatalidade?
}

\author{
Telma Ribeiro Garcia *
}

\begin{abstract}
RESUMO - Discute-se a adequação dos Diagnósticos de enfermagem à problemática psicossocial das gestantes adolescentes solteiras, captada a partir das representações destas gestantes sobre o seu vivido humano e social. Conclui-se que os Diagnósticos de Enfermagem, quando aplicados à problemática psicossocial da clientela, necessitam ser complementados com subsídios que facilitem a compreensão e a interpretação dos dados.
\end{abstract}

ABSTRACT - The adequacy of Nursing Diagnosis has been discussed to the unmarried pregnants teenagers psychosocial problematic, capted from the representation of these pregnants about their human and social living. it has been concluded that the Nursing Diagnosis, when applied to clientela's psychosocial problems, need to be complemented by subsidies that make easier the comprehension and interpretation of the data.

\section{INTRODUÇĀO}

Os dados que foram utilizados como foco deste trabalho fazem parte de dissertação elaborada por GARCIA ${ }^{5}$ e apresentada à Escola de Enfermagem da Universidade de São Paulo, para obtenção do grau de Mestre em Enfermagem, área de concentração em Enfermagem Obstétrica e Neonatal.

Conforme proposto originalmente, visou estudar a problemática psicossocial da gestante adolescente solteira não sob o ponto de vista explicativo-causal, mas do ponto de vista compreensivo, no qual a gestante se apresenta ao pesquisador como se afirmasse: "Eu sou eu, minha gestação e minhas circunstâncias". Desta forma, cada gesto, atitude, preocupação, queixas, cada sentimento ou idéia têm um significado que só pode ser avaliado em função do ser histórico-social que a gestante adolescente solteira, $e$.

Para o trabalho que se apresenta agora, aqueles dados foram reelaborados no sentido de testar a adequação dos Diagnósticos de Enfermagem à problemática psicossocial de gestantes adolescentes solteiras.

Os objetivos deste trabalho, portanto, são:

- conhecer as representações de um grupo de gestantes adolescentes solteiras sobre aspectos de sua problemática psicossocial;

- aplicar, aos dados obtidos, Diagnósticos de Enfermagem relacionados ao padrão de resposta humana ESCOLHER;

- analisar a aplicabilidade dos Diagnósticos de Enfermagem à problemática psicossocial de gestantes adolescentes solteiras.

\section{REFERENCIAL TEÓRICO-METODOLÓGICO}

Para se captar as representações das gestantes adolescentes solteiras sobre a problemática psicossocial que vivenciavam, partiu-se do princípio de que as experiências individuais, as histórias de vida, não se processam de forma isolada, mas expressam uma experiência coletiva. Como afirma SCHUTZ", "somente uma parte muito pequena do meu conhecimento do mundo se origina de minha experiência pessoal. A maior parte é derivada do social, dada por seus amigos, meus pais, meus professores e os professores dos meus professores".

O conhecimento do mundo $\epsilon$, portanto, uma construção social. Neste sentido, "todas as culturas têm um conjunto de comportamentos considerados mais apropriados aos valores que a sociedade deseja conservar ou transmitir. Sabe-se que tais comportamentos são obtidos fundamentalmente através do processo de socialização, ao qual a criança é submetida desde que nasce" (DELGADO et al. ${ }^{2}$ ).

\footnotetext{
* Mestre em Enfermagem Obstétrica, Prof. Adjunto III do Departamento de Enfermagem de Saúde Pública e Psiquiatria/Universidade Federal da Paraíba
} 
Esse processo inclui a diferenciação de comportamentos considerados apropriados para as crianças conforme sejam elas meninos ou meninas, sendo a partir dele que se constrói a identidade, "elemento-chave da realidade subjetiva e elo de ligação entre o indivíduo e a estrutura social, e que se reveste de um caráter historico na medida em que se forma na história de vida do individuo" (VIOLANTE, $\left.{ }^{10}\right)$.

Visto sob este ângulo, o problema da gestação em adolescentes, especialmente quando solteiras, torna-se complexo, não podendo a gestação ser definida como resultante deste ou daquele fator isolado, ou como tendo esta ou aquela consequência específica.

Para uma melhor compreensão, deve-se ter em mente a realidade concreta dessas gestantes - realidade historicamente determinada e de onde avulta a questão das condições em que se dá, em nossa sociedade, a socialização da mulher; em que ela constrói e é reforçada a sua identidade social/sexual.

Preconceitos vigentes em nossa sociedade contra a mulher fazem com ista só consiga ser definida através da famnia, ora como filha, ora

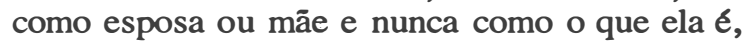
uma mulher que também desempenha outros papeis sociais.

As aspirações das meninas, construrdas a partir dessa trama, devem estar voltadas para o casamento, para terem filhos, para o futuro marido, enfim, que desfrutará de todas as suas "prendas". A ênfase na maternidade, ou seja, a equação mulher/mãe, significa, na prática, que é bom para as mulheres ficarem grávidas e terem filho, cuidando deles depois de nascidos, constituindo-se um desvio, uma anormalidade não dese jar isto.

Sob esse aspecto, a maternidade $\varepsilon$ um "destino biológico inevitável" para as mulheres. Destino inevitável, segundo FERREIRA ${ }^{4}$, é sinônimo de fatalidade que, por sua vez, é sinônimo de acontecimento funesto, infortúnio.

Quando se coloca o problema da maternidade na adolescência como escolha ou como fatalidade, parte-se do princípio que a escolha pressupõe ou envolve um ato ou operação racional que permite a opção entre duas possibilidades - ser mãe ou não ser mãe, independentemente do condicionamento cultural que induz a mulher à aceitação passiva de fecundação.

$\mathrm{O}$ primeiro aspecto - a escolha - se refere à capacidade racional que permite à mulher atuar sobre seu corpo. Implica em conhecimento do corpo, dos seus ritmos biológicos e em autonomia de decisão. $\mathrm{O}$ segundo - a fatalidade leva a mulher a uma atitude que lhe é socialmente imposta, para que, a partir de determinado momento e em determinadas circunstâncias (como a do casamento), ela tenha filhos
(PRADO, $\left.{ }^{8}\right)$.

A esta altura, alguns devem estar se perguntando o que tudo isto tem que ver com os Diagnósticos de Enfermagem.

Sob o ponto de vista da metodologia utilizada, esta abordagem propícia à Enfermagem uma maneira de encarar o problema diferente das usuais, abrindo uma nova diretriz com relação à atenção à saúde da mulher. Significa um novo tipo de relação paciente mulher/enfermeiro, onde as questões referentes ao corpo e às práticas que sobre ele incidem passam a emergir: o que se visa, se sente e se pensa em relação à realidade vivida deve ter seu espaço de expressão assegurado.

Conforme documento elaborado pelo INAN/MS (1983), "escutar o que a mulher traz e como traz, o que faz sofrer e incomoda é condição para que o profissional de saúde possa, junto com ela, localizar de que forma seu saber especffico pode ser útil. Quando se nega a singularidade de cada indivíduo e a elaboração própria de sua história socialmente vivida, se impede que o contato com os profissionais de saúde possa atender as expectativas de quem o procuroủ' .

No quadro atual, nem a população é atendida de forma satisfatória e nem os profissionais de saúde se satisfazem com o seu trabalho. Nega-se a experiência de vida da clientela e desqualifica-se o saber profissional em função das normas de sua eficiência.

Tem que ver com os Diagnósticos de Enfermagem dado que, na nona Conferência da NANDA (North American Nursing Diagnosis Association) realizada em 1990, estes foram definidos como "julgamento clínico das respostas do indivíduo, da famnlia ou da comunidade aos processos vitais ou aos problemas da saúde atuais ou potenciais, os quais fornecem a base para a seleção das intervenções de enfermagem, para atingir resultados, pelos quais o enfermeiro é responsável" (FARIAS et al. ${ }^{3}$ ).

\section{MATERIAL E MÉTODO}

A população do estudo foi constituŕda por primigestas, na faixa etária de 12 a 18 anos (adolescentes), com idade gestacional igual ou superior a 20 semanas e que compareceram, de janeiro a junho de 1984, durante o período matutino, ao Serviço de Prá-Natal do Amparo Maternal, instituição de saúde localizada no bairro de Vila Mariana, município de São Paulo-SP.

A escolha desta instituição para a realização da pesquisa foi determinada pelo criterio numérico: trata-se de instituição para onde converge a grande maioria das mães solteiras do munićpio, o que facilitou o contato com a população estudada. 
Pretendia-se que a apreensão da problemática psicossocial da gestante adolescente solteira se realizasse a partir de suas representações sobre a realidade que vivenciava, e que essa apreensão surgisse por meio de contatos semiestruturados e sucessivos, devendo cada contato assumir a forma de uma entrevista aberta. A estratégia que se utilizou para a ocorrência dos encontros foi a de realizar a assistência pré-natal das gestantes que eram selecionadas para o trabalho.

As entrevistas foram realizadas com base em dois procedimentos. No primeiro contato, a entrevista era de maior duração - em média uma hora e meia para cada gestante - e, nessa ocasião, utilizava-se o gravador. Nos contațos subseqüentes, os dados complementares à primeira entrevista eram anotados após o encontro.

No espaço de tempo que se destinou à seleção das participantes não ocorreu o comparecimento, ao Serviço de Prá-Natal, de gestantes adolescentes solteiras com idade inferior a 15 anos, ficando o estudo restrito à participação de gestantes com idade de 15 a 18 anos: uma com 15 anos; uma com 16 anos; quatro com 17 anos; e duas com 18 anos.

Para a apresentação dos resultados na dissertação de Mestrado, as informações obtidas dos discursos das gestantes adolescentes solteiras foram submetidas a uma descrição do tipo qualitativo, utilizando-se para tanto seus discursos em linguagem original.

No trabalho que ora se apresenta, essas informações foram selecionadas e agrupadas em torno dos Diagnósticos de Enfermagem oficialmente aprovados pela NANDA - TAXONOMIA I REVISADA - 1989, relacionados ao padrão de resposta humana ESCOLHER, conforme apresentados e descritos por FARIAS et al. ${ }^{3}$ e por NÓBREGA ${ }^{7}$.

\section{RESULTADOS}

Segundo a literatura consultada sobre os Diagnósticos de Enfermagem, citada no item anterior, o padrão de resposta humana ESCOLHER tem, que ver com selecionar alternativas; selecionar ou exercitar preferência por um assunto em que a pessoa é um livre agente; determinar a escolha em favor de uma direção; decidir em concordância com inclinações.

Para este padrão, foram, até o momento, oficialmente aprovados pela NANDA os seguintes Diagnósticos de Enfermagem:

\section{- LIDAR INEFICAZ: INDIVIDUAL (1978)}

Dificuldade do indivíduo para apresentar comportamento adaptativos e habilidade na resolução de problemas para atender as demandas e os papéis da vida.

- ADAPTAÇÂO PREJUDICADA (1986)

Estado em que o indivíduo é incapaz de modi- ficar seu estilo de vida ou comportamento, de um modo consciente, diante de uma mudança no seu estado de saúde.

\section{- LIDAR DEFENSIVO (1988)}

Estado em que um indivíduo repetidamente projeta uma auto-avaliação positiva, baseada em um padrão de autoproteção, que o defende contra ameaças interiores percebidas, para tornar positivas a autoconsideração.

- NEGAÇÃO INEFICAZ (1988)

Estado consciente ou inconsciente em que o indivíduo tenta negar o conhecimento ou o significado de um evento, para reduzir a ansiedade ou medo, prejudicando a sua saúde.

- LIDAR FAMILIAR INEFICAZ: INABILIDADE (1980)

Comportamento de pessoa significativa (membro da famflia ou outra pessoa primária) que dificulta as suas próprias capacidades e as do cliente para, efetivamente, enfrentar questões essenciais à adaptação de ambas ao desafio de saúde.

- LIDAR FAMILIAR INEFICAZ: COMPROMETEDOR (1980)

Uma pessoa primária, usualmente de apoio (membro da famnlia ou amigo chegado), está provendo suporte ou apoio, conforto, assistência ou encorajamento insuficientes, inefetivos ou comprometedores, os quais podem ser necessários para o cliente lidar ou superar tarefas adaptativas relacionadas com o desafio de sua saúde.

- LIDAR FAMILIAR: POTENCIAL PARA CRESCIMENTO (1980)

Efetivo domínio em questões adaptativas, exercidas por membro familiar envolvido pelo desafio de saúde do cliente, o qual agora está demonstrando desejo e disposição para promover saúde e crescimento, em relação a si e ao cliente.

- RECUSA (ESPECIFICAR) (1973)

Estado em que uma pessoa, informada de uma decisão, não adere à terapêutica recomendada.

- CONFLITO DE DECISĀO (ESPECIFICAR) (1988)

Estado de indecisão a respeito do curso de ação a ser tomado, quando a escolha entre ações competitivas envolve risco, perda ou desafio aos valores de vida pessoal.

- COMPORTAMENTOS PARA ELEVAR NÍVEL DE SAÚDE (ESPECIFICAR) (1988)

Estado em que o indivíduo em boas condições de saúde está, ativamente, buscando maneira de alterar hábitos de saúde pessoal e/ou ambiental, para atingir um nível mais elevado de saúde.

São estes os diagnósticos para os quais se buscou verificar a aplicabilidade à problemática das gestantes adolescentes solteiras. Os resultados obtidos estão descritos no quadro a seguir. 


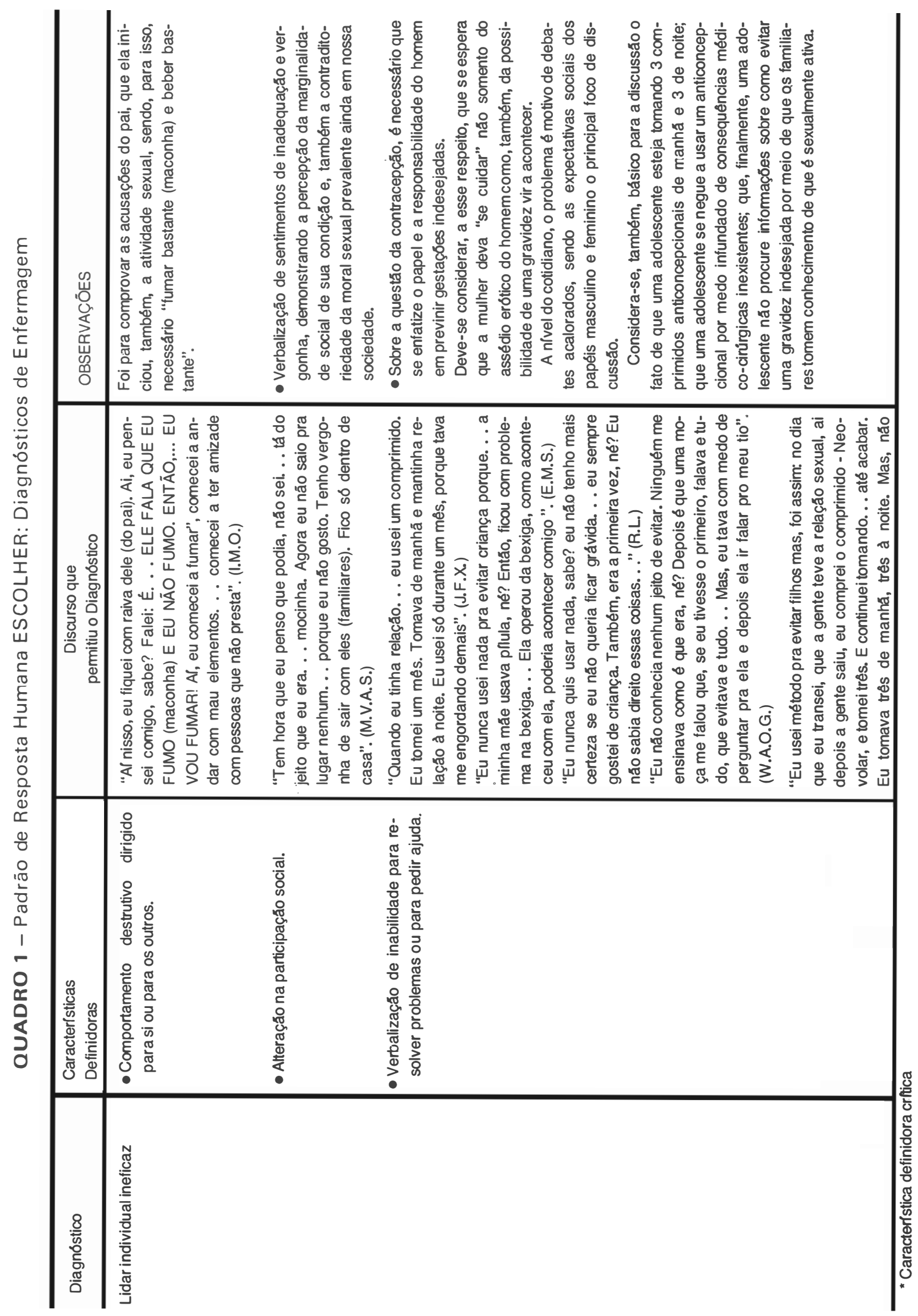

R. Bras. Enferm., Brasflia, 45 (1): 44-53, jan./mar. 199247 


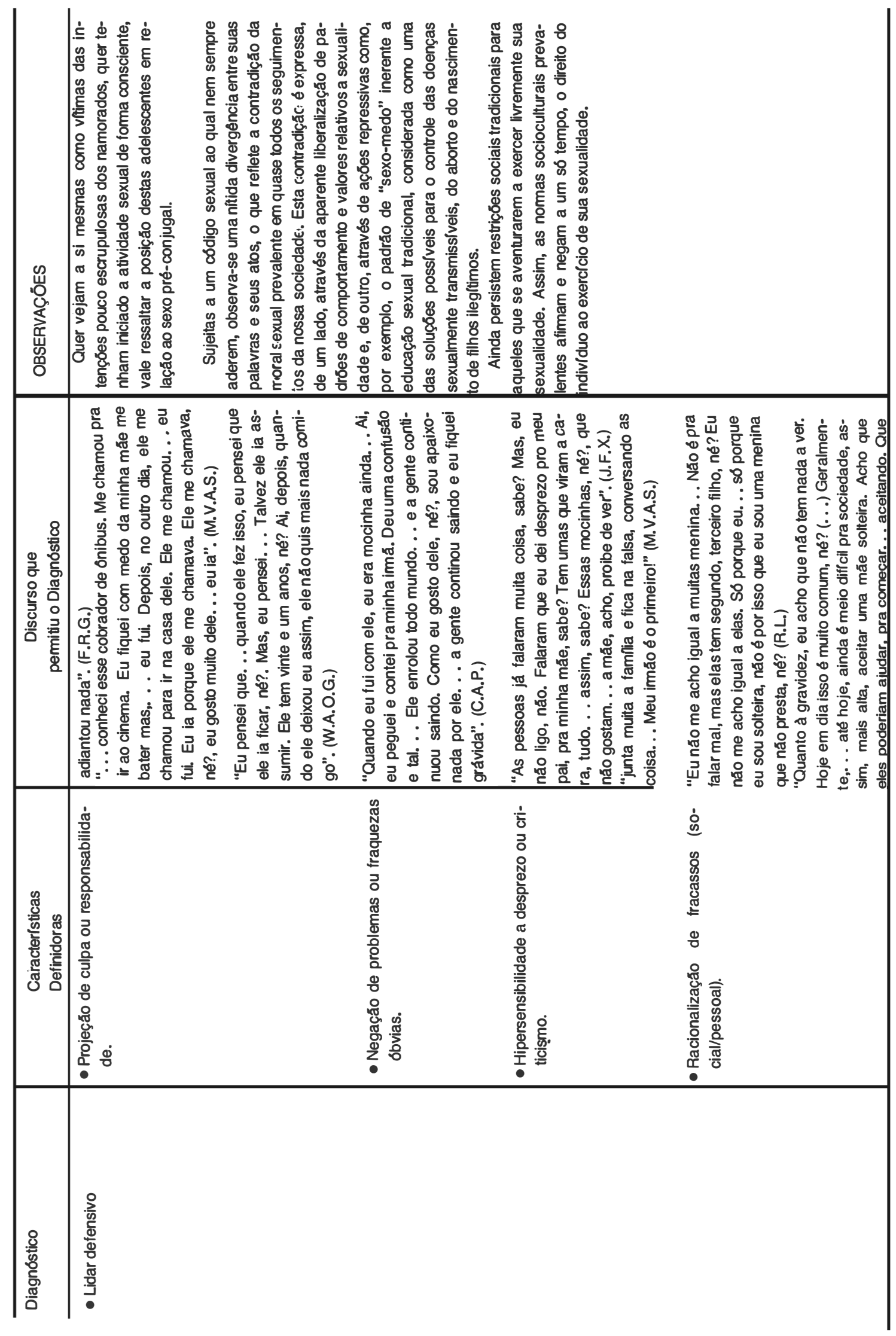




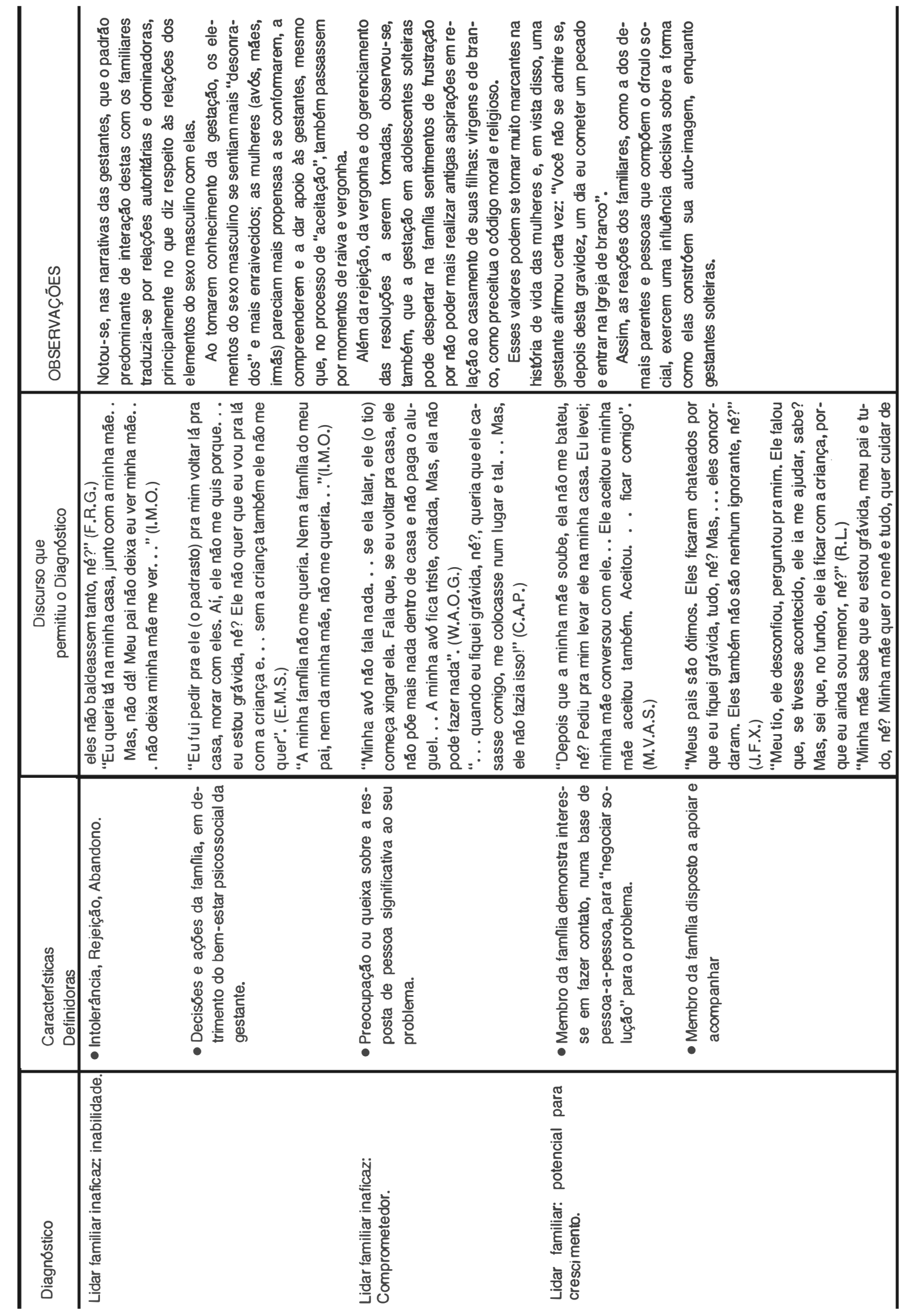




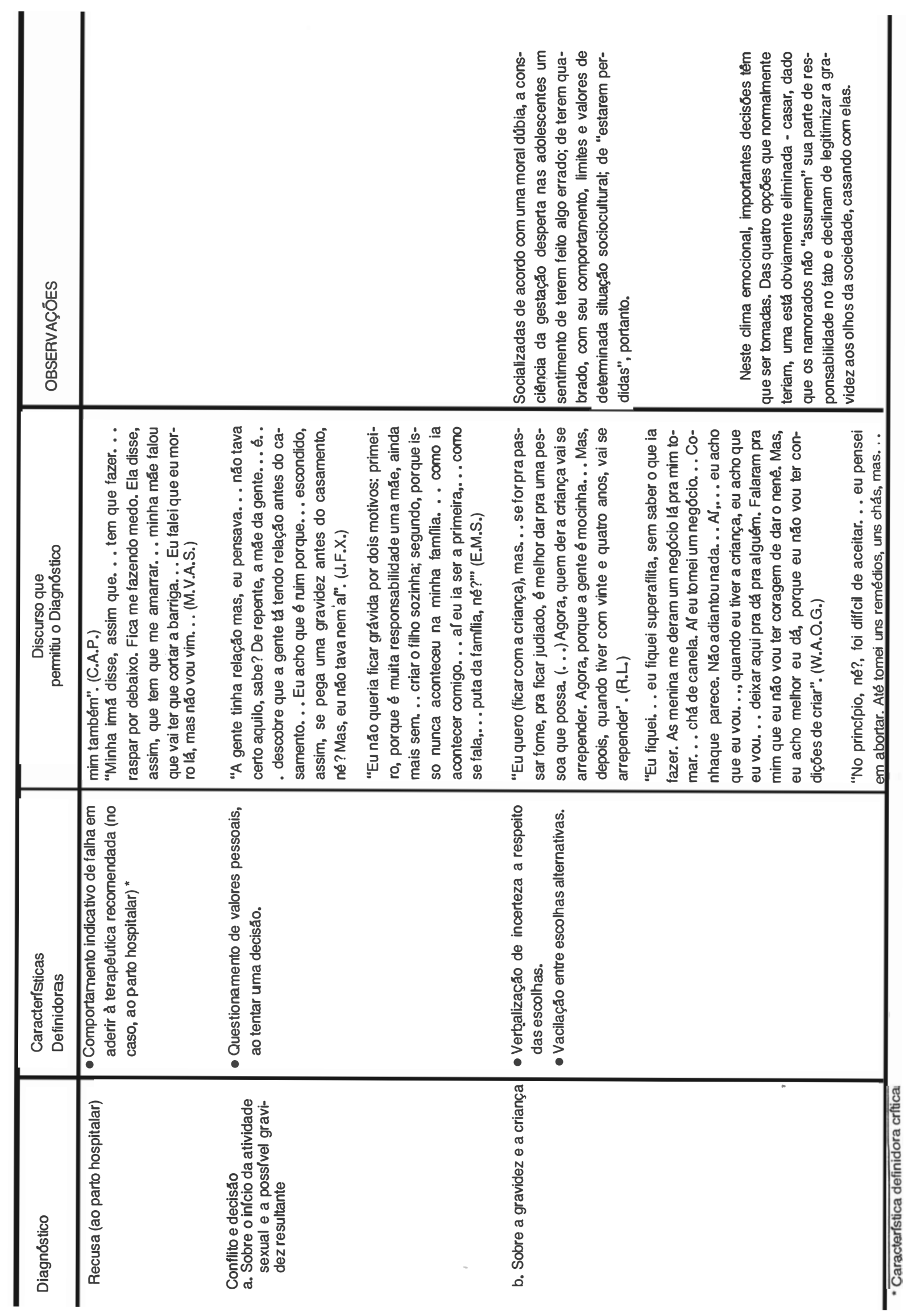

50 R. Bras. Enferm., Brasília, 45 (1): 44-53, jan./mar. 1992 


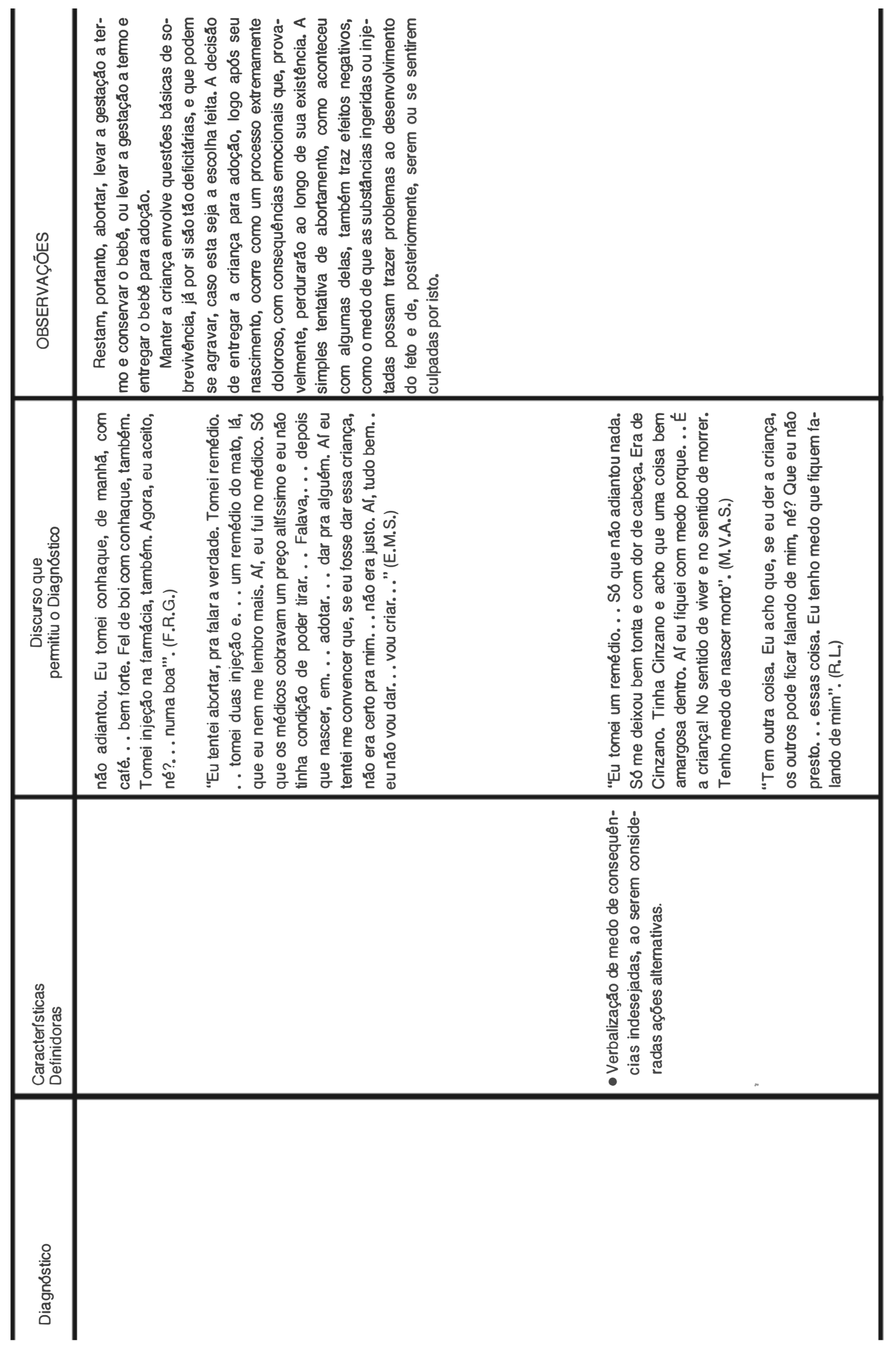

R. Bras. Enferm., Brasília, 45 (1): 44-53, jan./mar. 199251 


\section{CONSIDERAÇŌES FINAIS}

Além dos Diagnósticos de Enfermagem relacionados ao padrão de resposta humana ESCOLHER, descritos anteriormente, outros Diagnósticos relativos a outros padrões de resposta humana podem ser identificados ao se analisar as narrativas das gestantes adolescentes solteiras do estudo.

Assim, por exemplo, no padrão de resposta humana SENTIR, pode-se diagnosticar Ansiedade, que se traduz, na narrativa de uma das gestantes, como sentimento de inadequação após a primeira relação sexual: "Eu me senti estranha porque. . . não sabia o que era aquilo. . . Depois, ele me contou que era uma coisa que se chamava TRANSAR" (M.V.A.S.); , Medo das dores do parto: "Diz que é a maior dor do mundo. . . Nossa!" ou de "não ter abertura para a criança" (J.F.X.).

No padrão de resposta humana RELACIONAR, pode-se diagnosticar Isolamento Social, definido como solidão experimentada pelo indivíduo, percebida como uma imposição de outros e como estado negativo e ameaçador: "Minha famflia não me queria. Nem a famılia do meu pai, nem da minha mãe, não me queria. Eu não tinha pra onde ir. . . quando foi à noite, eu tava com medo. .. " (I.M.O.).

No padrão de resposta humana PERCEBER, pode-se diagnosticar Distúrbio de Auto-estima, caracterizado por expressões de vergonha e culpa identificadas na maioria das narrativas: "Quando eu me perdi. ...", "Isso é pra gente aprender. ..", "Tenho vergonha de sair porque os outros fica me perguntando as coisas. .."; ou por auto-avaliação como incapaz de lidar com situações desagradáveis como a censura social: "Se for uma moça fraca, não. . . já vai. . . querer fazer o que eu fiz. . . abortar, pra vê se acaba um pouco com tudo"' (F.R.G.). Diagnostica-se, também neste padrão de resposta humana, a Impotência ou a Desesperança, tradutoras maiores do momento vivenciado pelas gestantes: "Se melhorar pra mim, tá bom demais. Se não, . . . eu não posso fazer nada!" (I.M.O.).
A título de conclusão, vale ressaltar a dificuldade que representou o enquadramento, dentro dos Diagnósticos de Enfermagem, de informações que se obteve a partir de uma perspectiva metodológica segundo a qual "o vivido humano e social é constiturdo de significados que recorrem a processos de compreensão e de interpretação e não de explicação" (CAPALDO, '). A partir, pois, de uma perspectiva fenomenológica e não funcionalista.

Neste sentido, apesar de passíveis de serem aplicados a problemas de ordem psicossocial, como aqueles que se identificou ao estudar a gestação em adolescentes solteiras, os Diagnósticos de Enfermagem pareciam limitar a compreensão e a interpretação pretendidas para os dados obtidos das narrativas das gestantes. Por causa disso, sentiu-se a necessidade de acrescentar ao quadro descritivo dos diagnósticos trechos do discurso das gestantes e, especialmente, observaçōes através das quais se pudesse vislumbrar a complexidade do seu vivido humano e social.

Aplicados sem esse recurso, os Diagnósticos representariam explicações cientificas do tipo "Se X, então Y" e a problemática psicossocial da clientela que a Enfermagem assiste não pode e nem deve ser entendida dessa forma.

Quanto à questão das gestantes solteiras, acredito, plagiando FRIEDRICH ENGELS, que "isto se decidirá quando uma nova geração tiver crescido: geração de homens que nunca em sua vida precisarão de comprar a preço de dinheiro, ou com a ajuda de outra força social qualquer, o abandono de uma mulher; geração de mulheres que nunca estarão no caso nem de se entregarem um homem por outras considerações que não sejam a do amor real, nem de se recusarem ao amado por medo das consequências sócio-econômicas desse abandono. Quando essas pessoas existirem, deixarão ao diabo a preocupação do que se crê hoje em dia que elas deverão fazer. Elas próprias criarão seus costumes e uma opinião pública apropriada para julgar a maneira de agir de cada um. E é tudo". 


\section{REFERÊNCIAS BIBLIOGRÁFICAS}

1 CAPALBO, Creusa. Algumas considerações sobre a fenomenologia que podem interessar ao serviço social. Debates Sociais, Rio de Janeiro, v.15, supl.8, p.58-66, ago. 1980.

2 DELGADO, Gilda Dione, et a l. Menor: um olhar feminista. Presença da Mulher São Paulo, n.19, p.10-11, abr./jun. 1991.

3 FARIAS, Juracy Nunes de, et al. Diagnóstico de Enfermagem: uma abordagem conceitual e prática. João Pessoa: Santa Marta, 1990.160 p.

4 FERREIRA, Aurélio Buarque de Holanda. Novo dicionário da língua portuguesa. 2. ed. rev. aum. Rio de Janeiro: Nova Fronteira, 1986. p.761.

5 GARCIA, Tebma Ribeiro. Representaçöes de gestantes adolescentes solteiras sobre aspectos de sua problemática psicossocial: implicações para a enfermagem obstétrica. São Paulo, 1984. 140 p. Dissertação(Mestrado) USP).
6 INAN/MS. Assistência integral da saúde da mulher: bases para uma prática educativa. Brasília, 1983. 24p. (material xerocado).

7 NÓBREGA, Maria Mirian Lima da. Diagnóstico de Enfermagem da NANDA e a teoria das necessidades hwonanas básicas de Horta. João Pessoa, 1991. 99p. Dissertação (Mestrado) UFPB.

8 PRADO, Maternidade: opção ou fatalidade? In: SOBRE DIREITOS DA REPROSEMINÁ, IRÃO HUMANA. 1985, Rio de Janeiro. Anais ... p.

9 SCHU TZ, Alfred. Fenomenologia e relaçōes sociais. Rio de Janeiro: Zahar, 1979. 319p.

10 VIOLAN TE, Maria Lúcia V. O dilema do decente malandro. 2. ed. São Paulo: Cortez, 1983. 196p. 